Supporting Information

\title{
Self-assembly of a $\beta$-cyclodextrin Bis-inclusion Complex into Highly Crystalline Fiber Network. An Effective Strategy for Null Aggregate Design
}

\author{
Nagaraj Nayak and Karical R. Gopidas *
}

*To whom correspondence should be addressed: gopidaskr@gmail.com 


\begin{tabular}{|c|c|c|}
\hline $\begin{array}{l}\text { Sl. } \\
\text { No. }\end{array}$ & Contents & $\begin{array}{l}\text { Page } \\
\text { No. }\end{array}$ \\
\hline 1. & $\begin{array}{l}\text { SYNTHESIS OF AD-AN-AD (REACTION SCHEME AND } \\
\text { EXPERIMENTAL PROCEDURE) }\end{array}$ & S3-S5 \\
\hline 2. & THE ${ }^{1}$ H NMR SPECTRUM OF MOLECULE 3 (IN SCHEME S1) & S6 \\
\hline 3. & SINGLE CRYSTAL STRUCTURE OF MOLECULE 3 (IN SCHEME S1) & S6 \\
\hline 4. & ${ }^{1} \mathrm{H} N M R$ of $A D-A N-A D$ & S7 \\
\hline 5. & ${ }^{13} \mathrm{C} N M R$ of $A D-A N-A D$ & S7 \\
\hline 6. & ESI-HRMS of AD-AN-AD & S8 \\
\hline 7. & FIGURE SHOWING THE ORIENTATION OF $\beta$-CD PROTONS & S8 \\
\hline 8. & $\begin{array}{l}\text { POSSIBLE MODES OF AN/ } \beta-C D \text { INCLUSION IN AD-AN-AD } / \beta-C D \\
\text { SYSTEM }\end{array}$ & S9 \\
\hline 9. & $\begin{array}{l}\text { ADDITIONAL TEM IMAGES AND SAED PATTERN OF AD-AN-AD/ } \\
\beta-C D \text { NANOFIBERS }\end{array}$ & S9 \\
\hline 10. & ADDITIONAL AFM IMAGES OF AD-AN-AD/ $\beta$-CD NANOFIBERS & S10 \\
\hline 11. & $\begin{array}{l}\text { MOLECULAR DIMENSIONS OF } \beta-C D \subset A D-A N-A D \supset \beta-C D \\
\text { COMPLEX }\end{array}$ & S10 \\
\hline 12. & SCHEMATIC REPRESENTATION OF POSSIBLE AGGREGATES & S11 \\
\hline
\end{tabular}




\section{Synthesis of AD-AN-AD (Reaction Scheme and experimental procedure)}

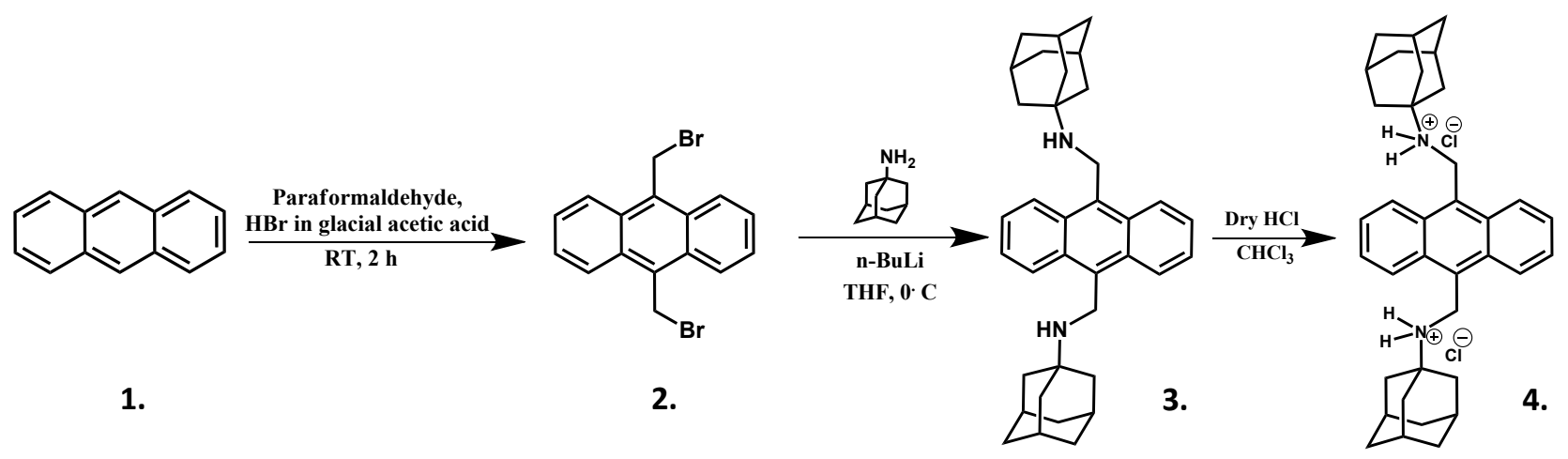

Scheme S1: Scheme for synthesis of AD-AN-AD

Synthesis of 2: Anthracene ( $5 \mathrm{~g}, 28 \mathrm{mmol})$ was dissolved in glacial acetic acid ( $30 \mathrm{ml})$ and to this $48 \% \mathrm{HBr}$ in acetic acid $(7 \mathrm{ml})$ and paraformaldehyde $(2.75 \mathrm{~g})$ were added. The mixture was stirred at RT for $12 \mathrm{~h}$. The yellow precipitate formed was filtered in Buchner funnel and washed several times with water. The dried compound was recrystallized in toluene to get pure 2 (Yield $=7.3 \mathrm{~g}, 71 \%$ ).

${ }^{1} \mathrm{H}$ NMR $\left(500 \mathrm{MHz}, \mathrm{CDCl}_{3}\right) \delta[\mathrm{ppm}]: 5.50(\mathrm{~s}, 4 \mathrm{H}), 7.68(\mathrm{~m}, 4 \mathrm{H}), 8.38(\mathrm{~m}, 4 \mathrm{H}) ;{ }^{13} \mathrm{C}$ NMR $(125$ $\left.\mathrm{MHz}, \mathrm{CDCl}_{3}\right) \delta[\mathrm{ppm}]: 26.6,124.4,125.4,126.7,127.7$

Synthesis of 3: To a stirred solution of 1-adamantalamine $(1 \mathrm{~g}, 6.61 \mathrm{mmol})$ in $50 \mathrm{ml}$ of dry THF at $0^{\circ} \mathrm{C}$, n-BuLi $(2.64 \mathrm{ml}, 2.5 \mathrm{M}, 6.6 \mathrm{mmol})$ was added in a drop wise manner under $\mathrm{Ar}$ atmosphere. The mixture was allowed to stir at $0^{\circ} \mathrm{C}$ for 30 minutes and after that compound $2(0.5 \mathrm{~g}, 1.37 \mathrm{mmol})$ was added. Then the mixture was allowed to stir at lab temperature for overnight. The reaction was quenched initially with little ethyl acetate and later with water and extracted into DCM. The organic layer was then separated, dried over anhydrous sodium sulphate and concentrated to get a yellow residue. This was further purified by 
column chromatography over $\mathrm{Al}_{2} \mathrm{O}_{3}$. Elution of column with $15 \%$ ethyl acetate $-85 \%$ Hexane gave compound 3 as a yellow solid. Yield: $0.43 \mathrm{~g}(61 \%)$.

${ }^{1} \mathrm{H}$ NMR $\left(500 \mathrm{MHz}, \mathrm{CDCl}_{3}\right) \delta[\mathrm{ppm}]: 8.3(\mathrm{~m}, 4 \mathrm{H}), 7.5(\mathrm{~m}, 4 \mathrm{H}), 4.7(\mathrm{~s}, 4 \mathrm{H}), 2.1(\mathrm{~s}, 6 \mathrm{H}), 1.9(\mathrm{~m}$, $12 \mathrm{H})$ and $1.6(\mathrm{~m}, 12 \mathrm{H}) .{ }^{13} \mathrm{C} \mathrm{NMR}\left(125 \mathrm{MHz}, \mathrm{CDCl}_{3}\right) \delta[\mathrm{ppm}]: 130.7,129.4,126.2,125,50.8$, 46.6, 41.6, 36.5 and 29.7 .

HRMS (ESI) Positive ion mode: $\mathrm{m} / z$ calc. for $\left[\mathrm{C}_{36} \mathrm{H}_{44} \mathrm{~N}_{2}+\mathrm{H}\right]^{+}$is 505.35 and found is 505.35 .

Synthesis of 4: Compound $3(1 \mathrm{~g}, 1.98 \mathrm{mmol})$ was dissolved in dry chloroform $(20 \mathrm{ml})$ in a $100 \mathrm{ml}$ round bottomed flask. To this solution freshly prepared $\mathrm{HCl}$ gas (by mixing $\mathrm{H}_{2} \mathrm{SO}_{4}$ and $\mathrm{NaCl}$ ) was passed under pressure for 10-15 minutes. The yellow precipitate formed was filtered and washed repeatedly with chloroform (until filtrate was colourless) to get pure final compound 4. Yield: $1.08 \mathrm{~g}$. (95\%). Melting point: decomposes at $285^{\circ} \mathrm{C}$.

${ }^{1} \mathrm{H}$ NMR $\left(500 \mathrm{MHz}, \mathrm{D}_{2} \mathrm{O}\right) \delta[\mathrm{ppm}]: 8.3(\mathrm{q}, 4 \mathrm{H}), 7.8(\mathrm{q}, 4 \mathrm{H}), 5.2(\mathrm{~s}, 4 \mathrm{H}), 2.3(\mathrm{~s}, 6 \mathrm{H}), 2.2(\mathrm{~s}, 12 \mathrm{H})$ and $1.8(\mathrm{~m}, 12 \mathrm{H}) .{ }^{13} \mathrm{C}$ NMR $\left(125 \mathrm{MHz}, \mathrm{D}_{2} \mathrm{O}\right) \delta$ [ppm]: 130.0, 127.4, 123.9, 99.9, 59.4, 38.1, 34.9 and 29.0.

HRMS (ESI), Positive ion mode: $\mathrm{m} / z$ calculated for $\left[\mathrm{C}_{36} \mathrm{H}_{46} \mathrm{~N}_{2}{ }^{2+}+\mathrm{H}^{+}\right]$is 507.37 . Found $\left[\mathrm{C}_{36} \mathrm{H}_{46} \mathrm{~N}_{2}{ }^{2+}+\mathrm{H}^{+}\right]=507.36(2 \%),\left[\mathrm{C}_{36} \mathrm{H}_{46} \mathrm{~N}_{2}{ }^{2+}+\mathrm{H}^{+}-2 \mathrm{H}\right]=505.358(4 \%)$ and $\left[\mathrm{C}_{36} \mathrm{H}_{46} \mathrm{~N}_{2}{ }^{2+}+\mathrm{H}^{+}-\right.$ $4 \mathrm{H}]=503.34(6 \%)$

Procedure for preparation of nanofibers: The compounds $A D-A N-A D$ and $\beta-C D$ were taken in the 1:2 ratios in double distilled water. The solution was heated to ensure dissolution of 
both the compounds and allowed to cool to room temperature. In the cooled solution we observed the spontaneous formation of nanofibers.

Procedure for preparation of thin films for WAXS analysis: The aqueous solution of AD-AN$A D / \beta-C D(1: 2$ ratio) at relatively higher concentration was drop cast on aluminium foil and allowed to air dry. The dried sample along with aluminium foil was used for X-ray analysis. 


\section{2. ${ }^{1} \mathrm{H}$ NMR of Molecule 3}

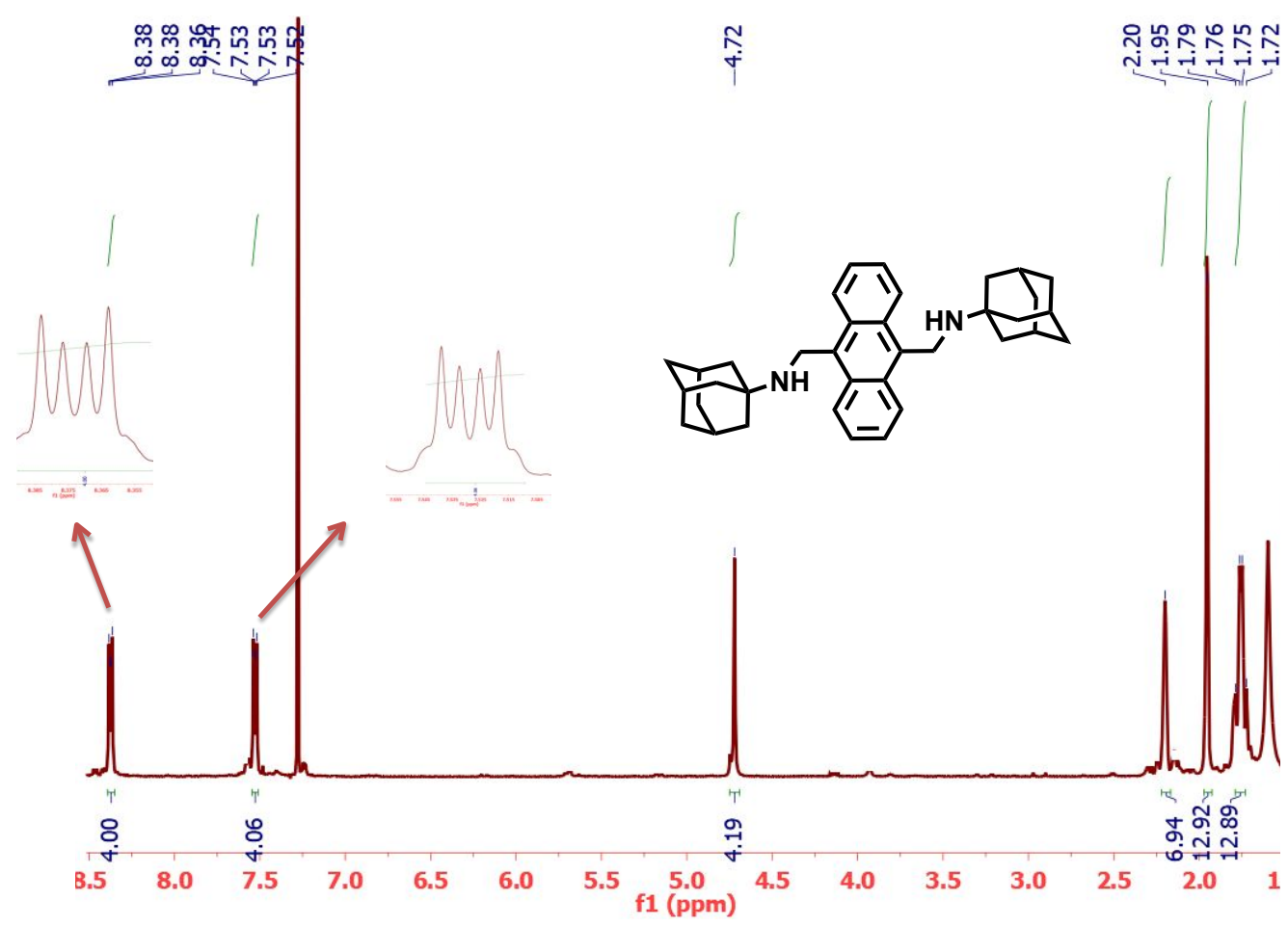

Figure S1 : The ${ }^{1} \mathrm{H}$ NMR Spectrum of Molecule 3 in Scheme S1.

\section{Single crystal structure of Molecule 3}

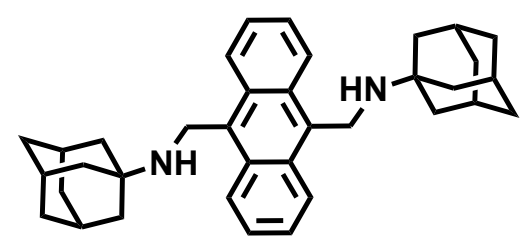

III

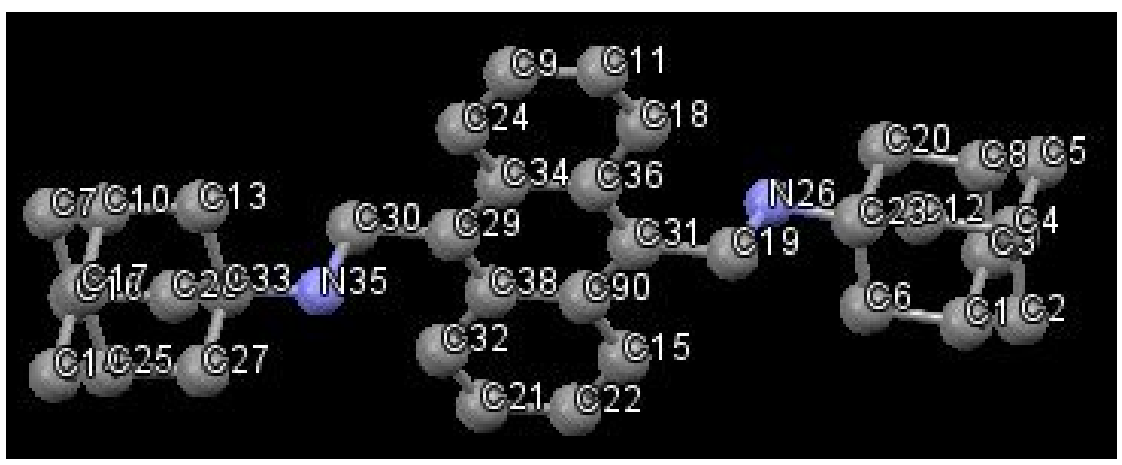

Figure S2 : The Single crystal Structure of Molecule 3 in Scheme S1. 


\section{4. ${ }^{1} \mathrm{H}$ NMR of AD-AN-AD}

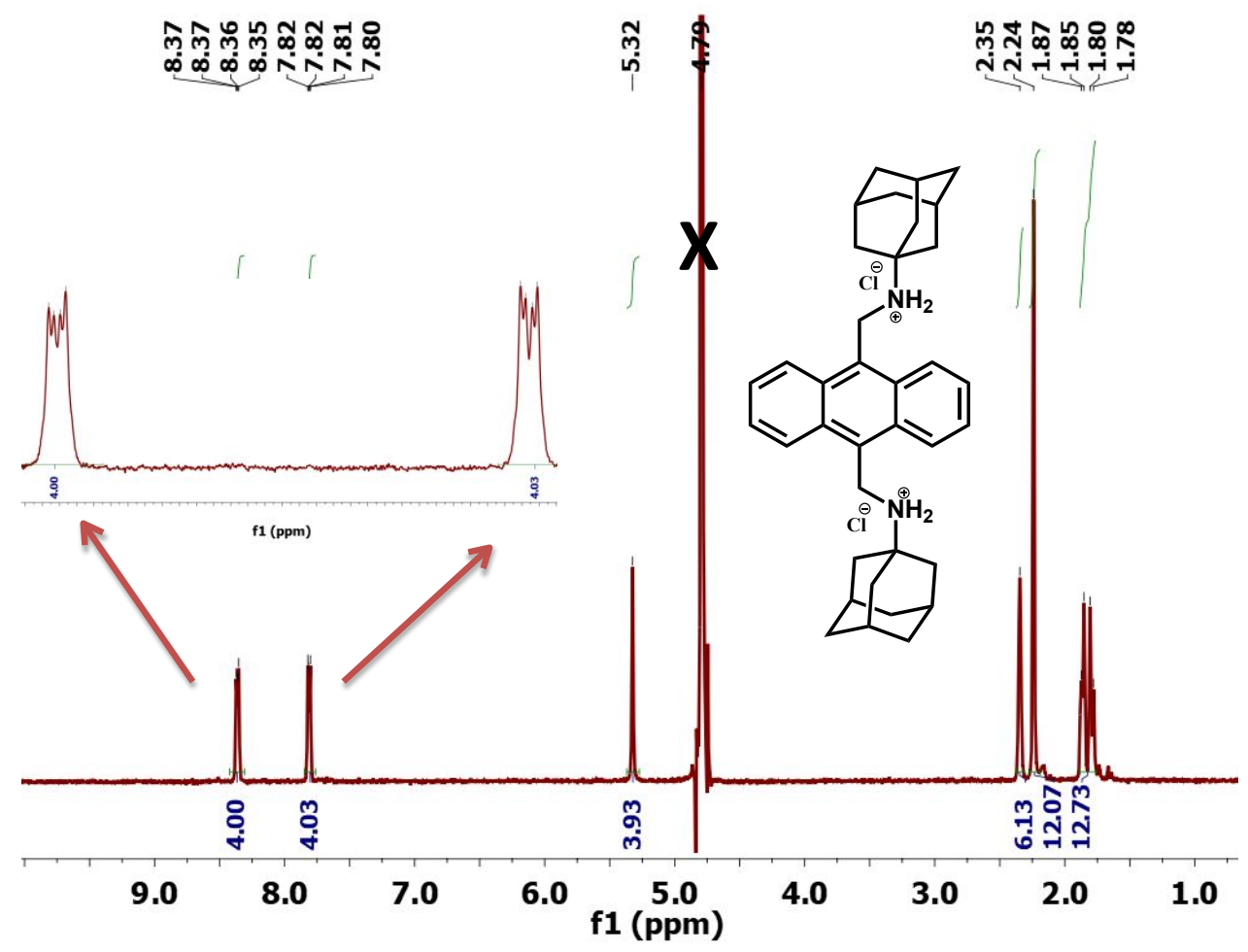

Figure S3 : The ${ }^{1} \mathrm{H}$ NMR Spectrum of AD-AN-AD

\section{5. ${ }^{13}$ C NMR of AD-AN-AD}

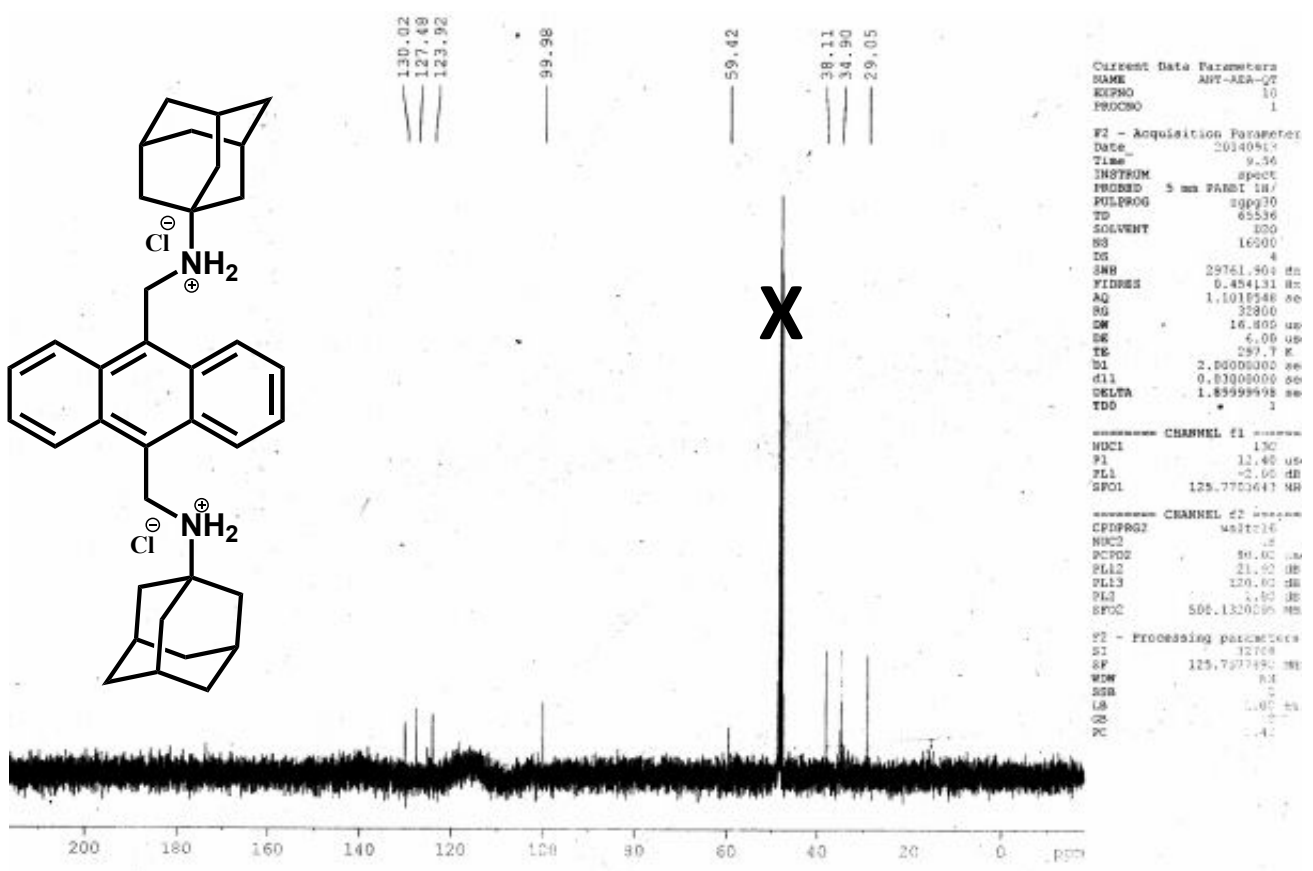

Figure S4: The ${ }^{13} \mathrm{C}$ NMR Spectrum of AD-AN-AD 


\section{ESI-HRMS of AD-AN-AD}

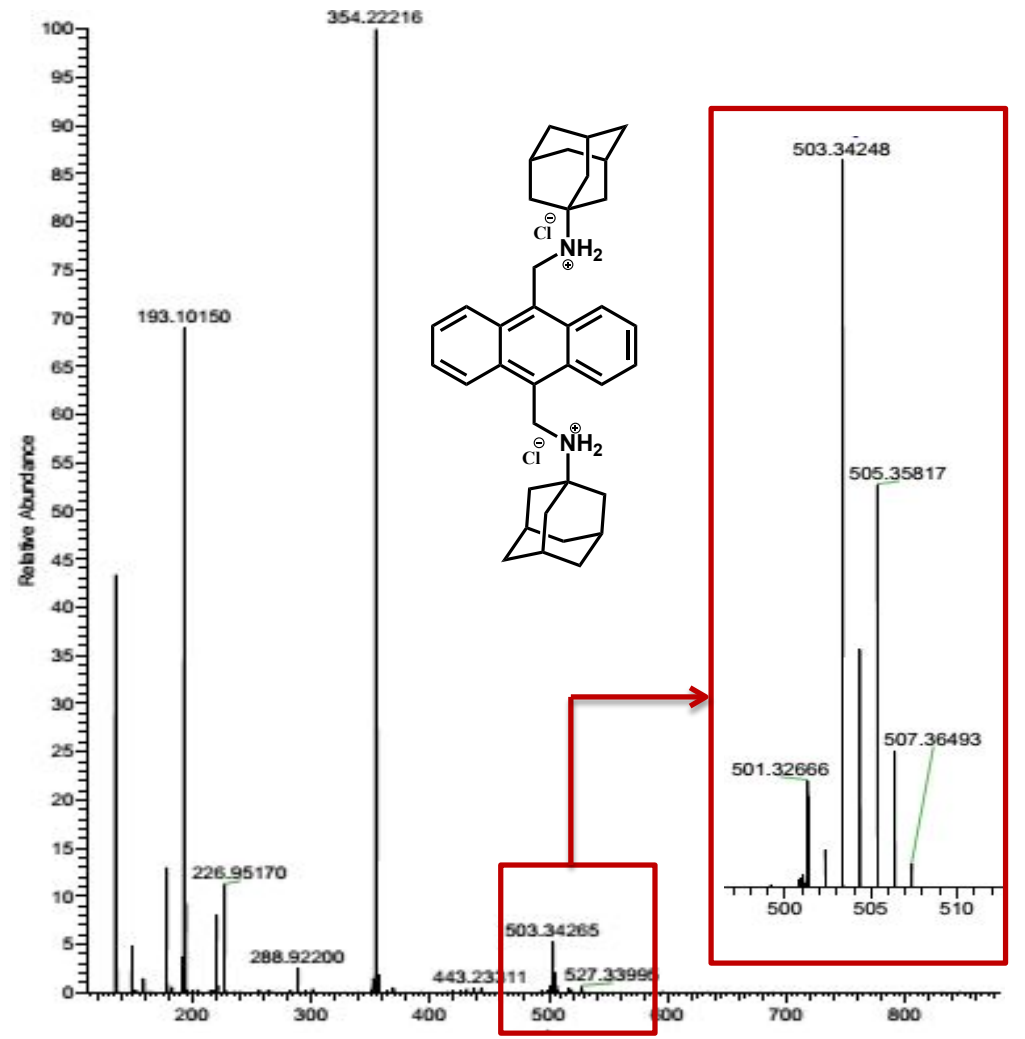

Figure S5: The ESI-HRMS of AD-AN-AD

\section{Figure showing the orientation of $\beta-C D$ protons}

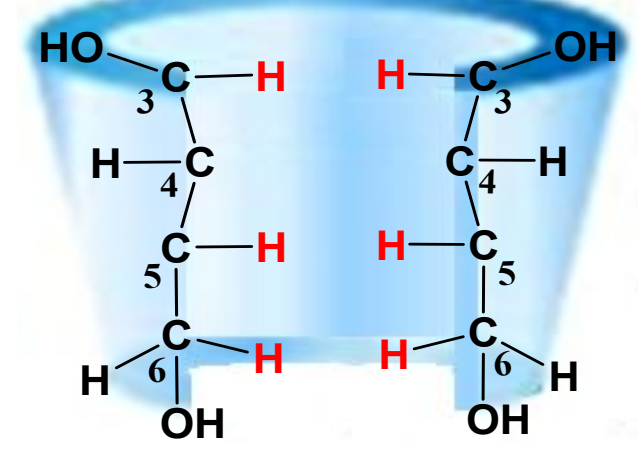

Figure S6. Representation of $\beta-C D$ showing its protons facing towards the interior (red) and exterior of the cavity (black). 
8. Possible modes of $A N / \beta-C D$ inclusion in $A D-A N-A D / \beta-C D$ system

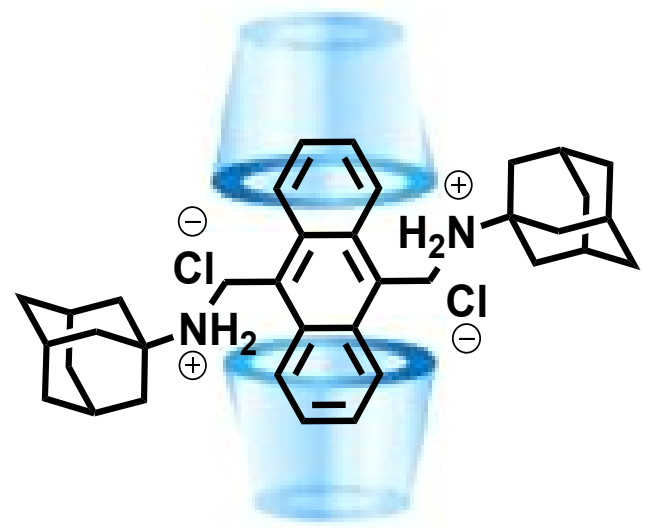

a

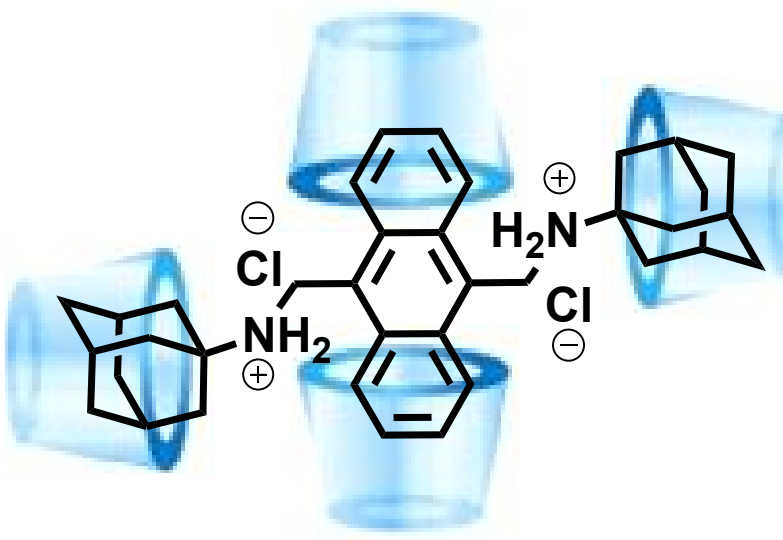

b

Figure S7. The two probable structures of host guest complex formation between $\beta-C D$ and $A D-A N-A D$, other than the one shown in Scheme 2 of main text.

\section{ADDITIONAL TEM IMAGES AND SAED PATTERN OF AD-AN-AD/ $\beta$-CD}

\section{NANOFIBERS}
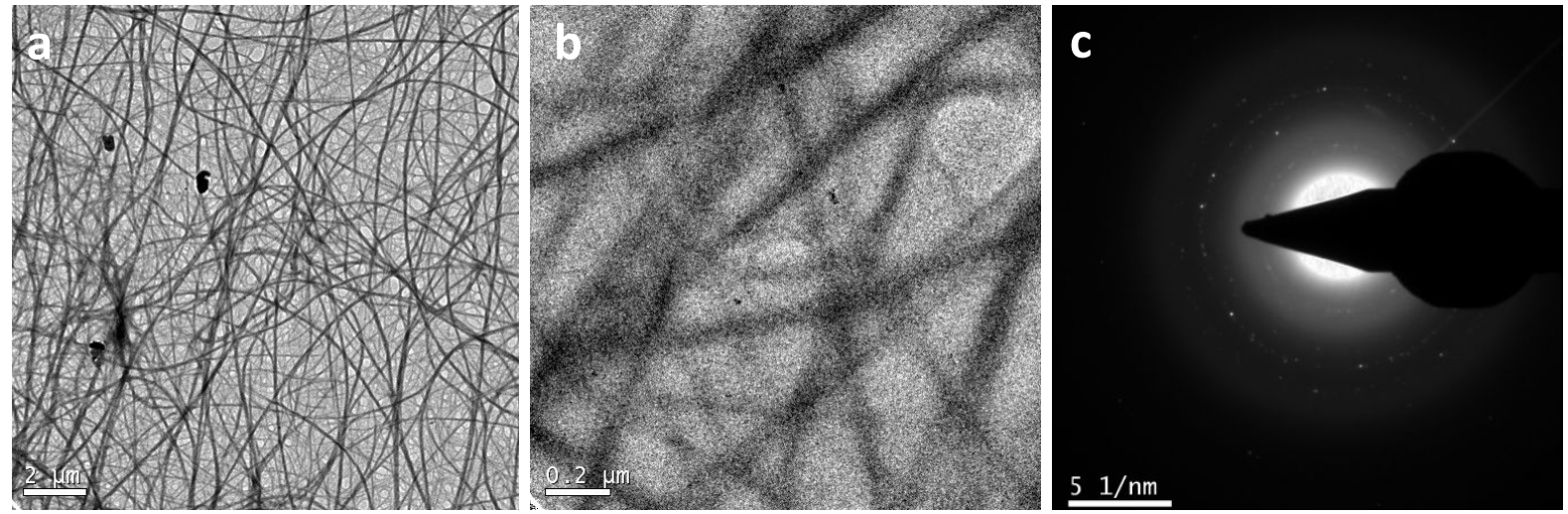

Figure S8. Additional TEM images $(a, b)$ and SAED pattern (c) of $\beta-C D \subset A D-A N-A D \supset \beta-C D$. [ $\beta-C D]=2 \times 10^{-5} M$, $[A D-A N-A D]=10^{-5} \mathrm{M}$ 


\section{ADDITIONAL AFM IMAGES OF AD-AN-AD/ $\beta$-CD NANOFIBERS}

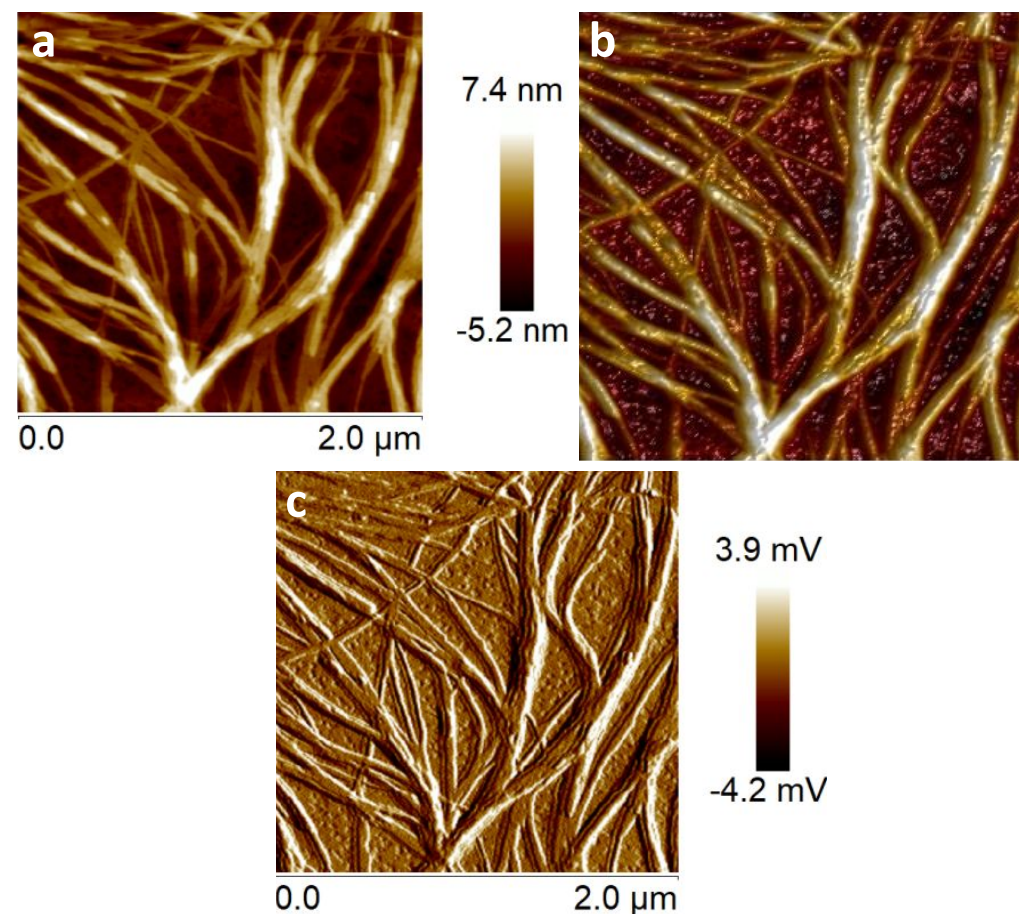

Figure S9. (a) AFM height, (b) AFM 3D and (c) AFM amplitude images of $\beta-C D \subset A D-A N-A D \supset \beta-C D$ nanofibers. $[\beta-C D]=2 \times 10^{-5} \mathrm{M},[\mathrm{AD}-\mathrm{AN}-\mathrm{AD}]=10^{-5} \mathrm{M}$.

\section{MOLECULAR DIMENSIONS OF $\beta$-CD $\subset A D-A N-A D \supset \beta-C D$ COMPLEX}

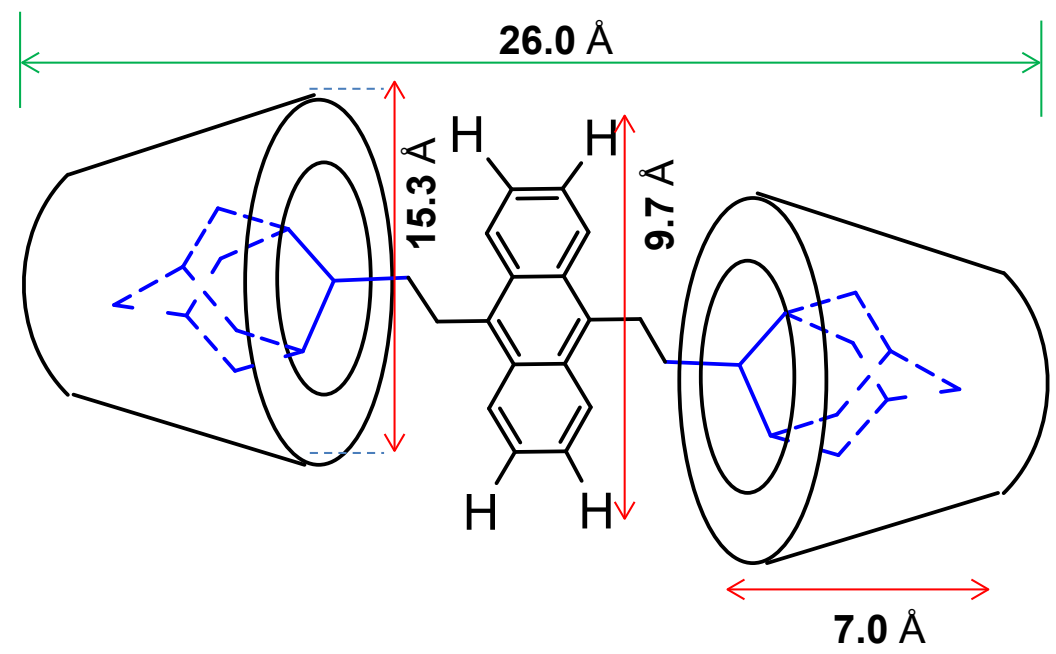

Figure S10: Structure and molecular dimensions of $\beta-C D \subset A D-A N-A D \supset \beta-C D$ complex. For the sake of clarity the $\mathrm{NH}_{2}^{+}$group is not shown. 
12. SCHEMATIC REPRESENTATION OF POSSIBLE AGGREGATES

a

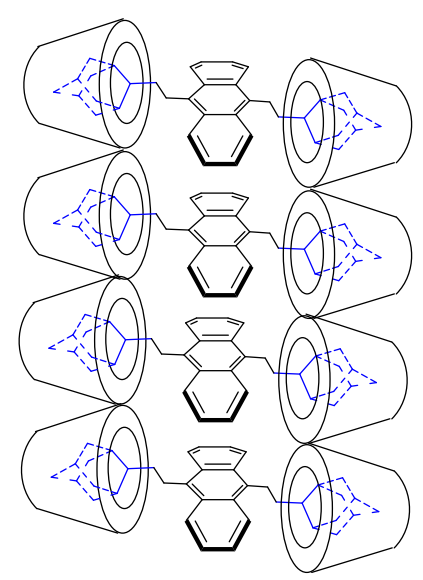

H-aggregate b

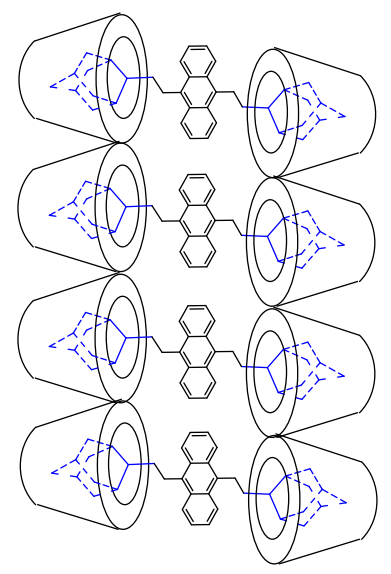

J-aggregate

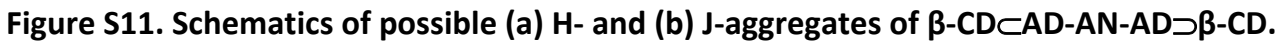

